\title{
Power Quality Improvements for an Electrical System with an Automobile Shredder
}

\author{
James R. Johnson \\ Product Manager - AHF \\ Schneider Electric-Power \\ Salem, Oregon USA \\ ijohnson@accusine.com
}

\author{
Remi Bolduc \\ PQC Specialist \\ Schneider Electric-Powe \\ Pringy, France \\ remi.bolduc@fr. \\ schneider-electric.com \\ Jean-Marc Lupin \\ Innovation \& Technology Mgr \\ Pringy, France \\ jean-marc.lupin@fr. \\ schneider-electric.com
}

\author{
Laurent Chenevard \\ Sales Application Engineer \\ Schneider Electric-Power \\ Pringy, France \\ laurent.chenevard@fr. \\ schneider-electric.com
}

\begin{abstract}
:
The quality of the power supplied by utilities today is effectively defined in the harmonic standards adopted by many countries or by local utility codes. This is primarily due to user demands for quality power so that user power interruptions are minimized.

Presented are numerous possible solutions to address flicker and a case study for an automobile shredder from the planning stages through measurements after installation. The solution chosen for this application will be discussed and presented.

Index terms: Active harmonic filter, hybrid VAR compensator, hybrid VAR compensation, flicker, power quality, total harmonic voltage distortion [THDV], VAR compensation
\end{abstract}

\section{INTRODUCTION}

Many types of electronic and power electronic devices are in use today due to the energy and labor savings generated by these devices. However, these devices are also contributors to the harmonic noise levels inside their respective facilities and at the utility level.

All harmonic and power quality standards presently in use worldwide deal with the level of disturbances seen at the utility. It is imperative that users and utilities both respect these standards so that optimization of power usage and improved productivity are achieved for all.

However, these standards do nothing to enhance performance for users when the problems are inside the users facilities. Compliance can be achieved by the users applying solutions within their plants or at the utility connection point. In general, when solutions are applied as close as possible to offending loads, an optimization of the facility and utility occurs.
One type of utility disturbance that is not necessarily caused by electronic loads is flicker. Flicker is the result of intermittent short term load demand for very high levels of active and reactive energy. This high demand results in intermittent voltage sags because these peak current demands are not able to be supported by the utility or the distribution transformers installed for the applications.

If the demand is for real current, the electrical system or distribution transformer must be made more robust. This could be supplied by auxiliary devices but are for the majority of sites best provided by the utility from a least cost perspective, unless a small proportion of loads is to be supported within a facility.

If the demand is for reactive current, there are several options to consider.

\section{POSSIBLE SOLUTIONS FOR FLICKER MITIGATION}

Some solutions are implemented at the load level. They can be:

Change the type of lighting by replacing incandescent lights with electronic fluorescent lamps which are less sensitive to voltage sags.

Install an uninterruptible power supply (UPS). This may be a cost-effective solution if loads subject to disturbances are identified and grouped together.

Modify the device generating the disturbance. For example, use soft starters on motors which have to start frequently. Soft starters reduce the starting current.

Other mitigation measures are targeted at actions focused on limiting the amplitude of the voltage fluctuations: 
European Association for the Development of Renewable Energies, Environment and Power Quality (EA4EPQ)
International Conference on Renewable Energies and Power Quality (ICREPQ'10)

Granada (Spain), 23rd to 25th March, 2010

VAR compensators to inject leading and lagging according to load demand.

\section{HYBRID VAR COMPENSATOR}

Increase the "electrical distance" between the disturbing loads and the lighting circuits by powering the disturbing loads from an independent transformer.

Use reactive compensation that provides real time capacitive reactive compensation for each phase.

Connect a series inductance on the disturbing load. This reduces the inrush current and smoothes the peak current demand.

However, if the flicker problem is occurring on the utility, there are generally, two methods of solution.

One method is to increase the short circuit capacity of the utility. This could be achieved by:

Connecting the offending loads at a higher voltage level on the utility;

Supply the offending loads from a dedicated utility supply;

Separate offending loads from other loads by using separate distribution transformers; or

Increase the kVA capacity or decrease the impedance of the supply transformer.

Another method is to reduce the reactive current fluctuations by compensation via auxiliary devices.

Installation of synchronous generators provides leading VAR.

Static VAR compensators inject leading current (capacitors) and lagging current (inductors).

Dynamic VAR compensation systems that use power electronics to inject leading and lagging reactive current upon demand.

Hybrid VAR compensators that use capacitors to inject leading reactive current and active
A hybrid VAR compensator (HVC) is a custom built product consisting of standard PF capacitors (detuned preferably) and a standard active harmonic filter (AHF) operating in reactive current mode only. They can be applied to systems rated up to $20 \mathrm{kV}$.

The purpose is to inject reactive current to replace what would normally be supplied by the utility. By doing so, the size and short circuit capacity of the utility supply need not be enlarged to prevent flicker. Alternately, it could also be that the flux of the supply transformer is saturating, thus causing the voltage sags.

The essence of the design is that the capacity of the AHF is equal to the capacity of the PF capacitors, except when the load may have a need for some level of fixed PF correction. This permits the AHF to cancel the leading reactive current of the PF capacitors by injecting lagging reactive current when no load demand exists. Then as the load demand increases for reactive current, the AHF adjusts instantly and reactive current flow to the loads so the source does have to provide it. The AHF can inject leading reactive current to double the reactance of the PF capacitor rating upon demand. This all occurs instantaneously per cycle of electricity. See Figure 1.

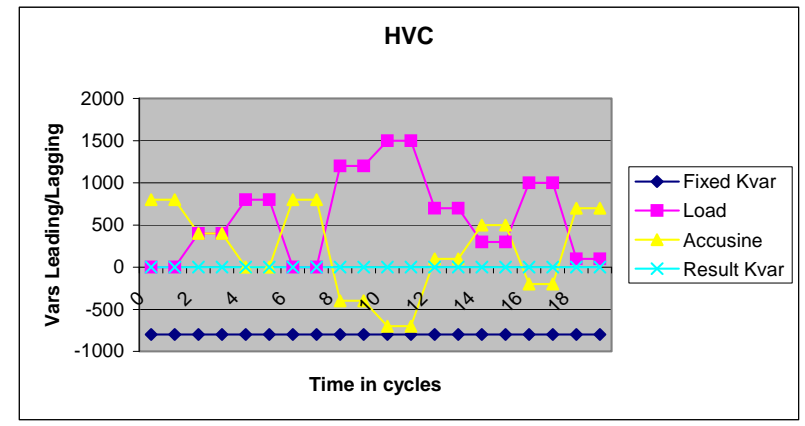

Figure 1: HVC Reactive Current Operation independently per phase to permit leading 
European Association for the Development of Renewable Energies, Environment and Power Quality (EA4EPQ)
International Conference on Renewable Energies and Power Quality (ICREPQ'10)

Granada (Spain), 23rd to 25th March, 2010

\section{CASE STUDY}

A recycling facility invested in a new automobile shredder to increase the production output (Figure 2). The project faced a major hurdle when the local French utility analysed the load profile of the shredder and determined that special precautions had to be taken to meet the flicker grid code.

Flicker levels are defined in standards or national regulations. As an example, EN 50160 requires that, under normal operating conditions, the long term flicker severity caused by voltage fluctuation should be equal to or less than a PIt (long term) of 1 for $95 \%$ of the time. IEC 610003-7 gives indicative planned levels for MV power systems of Pst (short term) $=0,90$ and PIt $=0,70$.

The limits for individual emission levels are generally defined by a contractual arrangement or by national regulations. As an example, limits for individual installations of Pst $=0,35$ and Plt $=$ 0,25 are required in France for installations connected to the distribution system.

The grid operator suggested a dedicated power line to feed the expansion. However, that would take several months to build and cost several hundreds of thousands of euros.

The automobile shredder (Figure 2) in question is equipped with hammers (2) fixed on the periphery of the cylinder called a "rotor". When metal enters the crusher, they are shredded by the hammers as they rotate. As each hammer strikes, the AC motor stalls until the hammer passes through the metal. When the AC motor stalls, the reactive current increases to 6 to 8 times the full load design current of most AC motors. Most utilities, designers and users fail to take this high pulsed load into consideration when the utility supply system is chosen.

These new facts threatened the project. After reviewing the requirements, it was proposed that a custom designed HVC system would meet the grid code flicker requirements that proved to be less costly and delivered in a timely fashion helping the end user complete the expansion on time within the allocated budget.

The AC motor for this application is rated 2350 $\mathrm{kW}$ at $6 \mathrm{kV}$. Table 1 lists the real power (kW), total apparent power $(\mathrm{kVA})$, reactive power
(kVAr), and Cos $\phi$ (displacement power factor). The rated levels are shown along with the calculations for three different types of overloads expected.

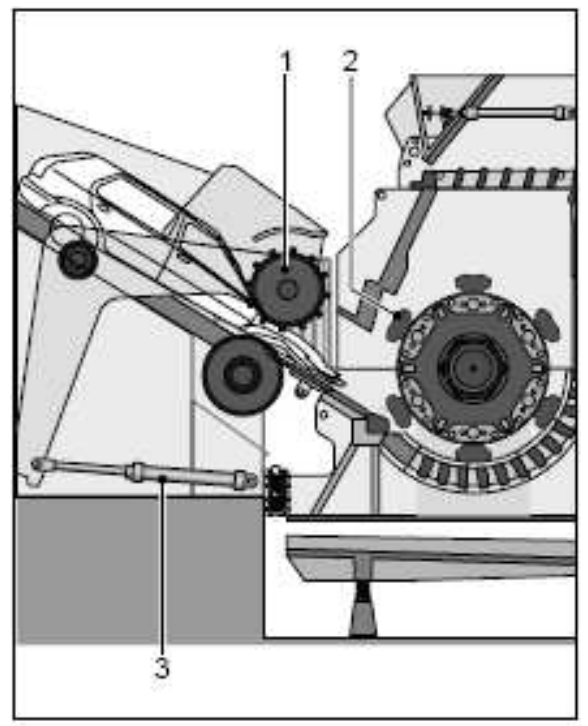

Figure 2: Automobile Shredder Machine

\begin{tabular}{|l|c|c|c|c|c|}
\hline Shredder & $P$ & $Q$ & $S$ & cos & $\begin{array}{c}\text { Number per } \\
\text { minute }\end{array}$ \\
\hline Nominal & {$[k W]$} & {$[k v a r]$} & {$[k V A]$} & \\
\hline Overload n9 & 2350 & 1332 & 2701 & 0.87 & \\
\hline Overload n2 & 2350 & 1820 & 2972 & 0.791 & 10 to 20 \\
\hline Overload n3 & 2350 & 3787 & 4457 & 0.527 & 1 \\
\hline
\end{tabular}

Table 1: Estimated current measurements during operation

\section{THE INVESTIGATION}

A study of the automobile shredder was conducted at the $6 \mathrm{kV}$ connection level to calculate the flicker levels and corresponding real, total, and reactive power requirements associated with the voltage sags.

Using the information provided by the shredder manufacturer and the utility, a model was constructed. For each mode of the shredder overloads, the voltage drop was estimated (Table 2). Also calculated was the maximum voltage drop allowed to achieve a Pst of 0.35.

The results show a need for a dynamic compensation system rated $2820 \mathrm{kVAr}$ connected directly to the 6kV bus. The system applied consists of a fixed de-tuned capacitor bank rated 1570 kVArc and an AHF rated +/$1250 \mathrm{kVAr}$ (figure 3). This solution makes it 
European Association for the Development of Renewable Energies, Environment and Power Quality (EA4EPQ)
International Conference on Renewable Energies and Power Quality (ICREPQ'10)

Granada (Spain), 23rd to 25th March, 2010 possible to compensate for the full inductive reactive power of the $A C$ motor during nominal operation (1332 kVAr) with 1488 kVAr left over to inject in real time during the shredder over load operation (estimated maximum need of 1357 kVAr required). That can be described by this simple expression: 1570 kVArc - 1332 kVAri +1250 kVArc $=1488$ kVArc.

\begin{tabular}{|l|c|c|c|c|}
\hline Voltage drop & nominal & overload & overload & overload \\
\cline { 3 - 5 } & & $\mathbf{1}$ & $\mathbf{2}$ & 3 \\
\hline$\Delta \mathrm{U} / \mathrm{U} \_20 \mathrm{kV}$ & $1.33 \%$ & $1.79 \%$ & $3.66 \%$ & $2.88 \%$ \\
\hline $\begin{array}{l}\text { Limit } \\
\Delta \mathrm{U} / \mathrm{U} \text { Pst }=0,35\end{array}$ & & $0.42 \%$ & $0.95 \%$ & $0.50 \%$ \\
\hline Qhvcmin_Pst=0,35 & & $\sim 0$ & $+1357 \mathrm{kvar}$ & $+1062 \mathrm{kvar}$ \\
\hline
\end{tabular}

Table 2: Projected Voltage Sags and kVAr Requirements

Based upon the above simulation, an HVC was designed for $6 \mathrm{kV}$.

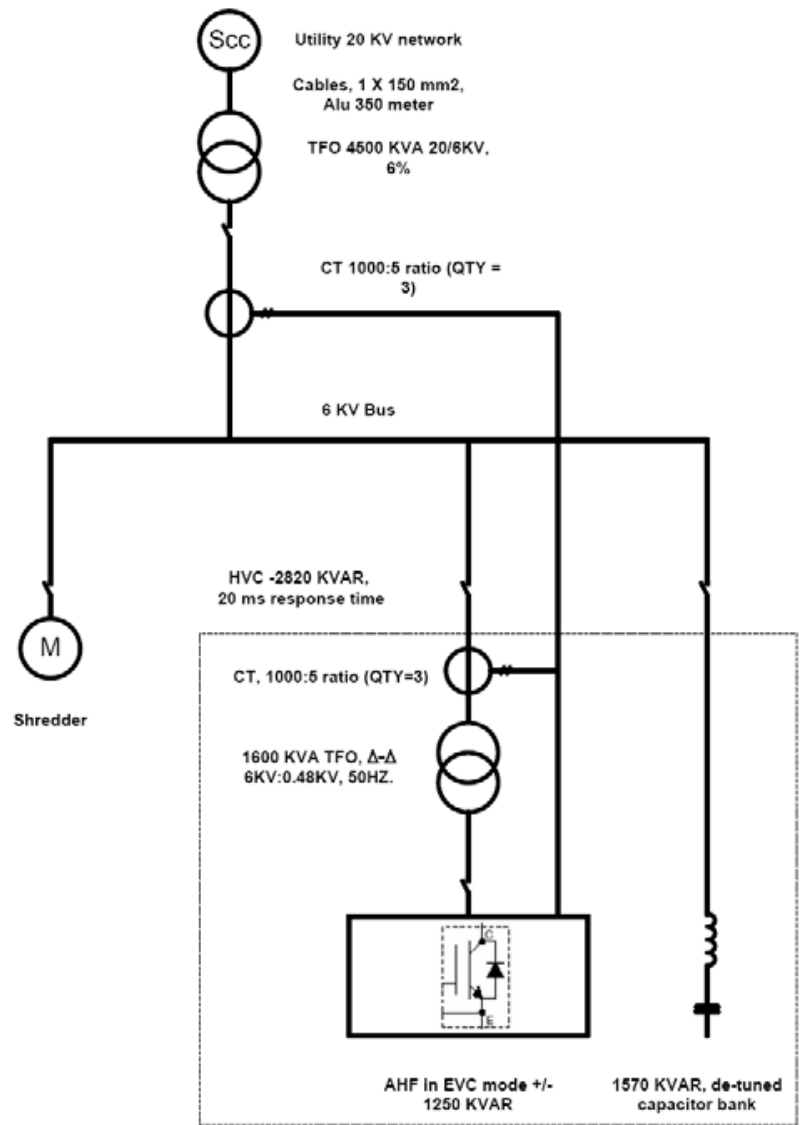

Figure 3: Electric One-line Drawing of Installation

\section{Installation Analysis}

Measurements were taken at the secondary of the $4500 \mathrm{kVA}$ 20:6 kV transformer. The results obtained are shown in Table 3.

\begin{tabular}{|l|c|c|c|c|}
\hline \multirow{2}{*}{$\begin{array}{l}\text { reasurement } \\
\text { results }\end{array}$} & \multicolumn{2}{|c|}{ Without HVC } & \multicolumn{2}{c|}{ With HVC } \\
\cline { 2 - 5 } PIt & Maximum & Value 95\% & Maximum & Value 95\% \\
\hline Cos(phi) & 1.498 & 0.629 & 0.46 & 0.40 \\
\hline THD(U) & & 0.874 & & 0.993 \\
\hline
\end{tabular}

Table 3: HVC performance results

The installed HVC rated 2820 kvar can limit the flicker induced on the network to well below a PIt of 1 .

The HVC system also corrects the displacement power-factor (Cos $\phi)$ of the installation to near unity. In fact, Cos $\phi$ is increased from 0.874 inductive in real time to 0.993 inductive; eliminating any PF penalty imposed by the energy supplier. Also, the use of a capacitor bank equipped with detuned reactor tuned to $215 \mathrm{~Hz}(50 \mathrm{~Hz}$ supply) attenuates most of the total harmonic voltage distortion on the network by partially filtering the $5^{\text {th }}$ harmonic current.

\section{CONCLUSIONS}

The HVC system installed on the automobile shredder helped meet the flicker grid code requirements and allowed the end user to complete their expansion project within the allocated budget and on time. Additionally, other power quality benefits were realized. The harmonic distortion in voltage and current was reduced and the PF penalty was alleviated creating a more energy efficient industrial work site.

HVC can also be used for crane and arc welder applications, as well as large AC motor sites with frequent starts, and other difficult applications.

The future development of the HVC will include a larger power range and voltage controls working in parallel with a Cos $\phi$ target requirement. 


\section{REFERENCES}

[1] Z. Hanzelka, A. Bien, 2006, Voltage disturbances Flicker, LPQI.

[2] EN 50160, 1999, Voltage Characteristics of Electricity Supplied by Public Distribution System.

[3] IEC TR 61000-3-7, 2008, Electromagnetic compatibility (EMC) -Part 3-7 Limits Assessment of emission limits for the connection of fluctuating installations to MV,HV and EHV power systems.

[4] R. Wierda 1995, Flicker ou scintillement des sources lumineuses, Cahier Technique Merlin Gerin CT176.

[5] P. Ferracci, 2001, Power Quality, Cahier Technique Merlin Gerin CT 199.

\section{Authors:}

James R. Johnson is a 1972 graduate of the University of Pittsburgh with a Bachelor of Science degree in Electrical Engineering. His experience includes 21 years of selling, applying, and servicing $A C$ \& DC motor speed controls with several companies including Robicon, Emerson Industrial Controls, and Control Techniques. Beginning in 1983, Jim worked extensively in providing harmonic mitigation equipment in conjunction with motor speed controls. Since 1993, he has worked exclusively in the power quality market specializing in power factor correction and harmonic mitigation equipment, with major emphasis on active harmonic filters. Jim has lead two companies into the active harmonic filter market via company start-ups. Jim is presently Product Marketing Manager for Active Harmonic Filters products for Schneider Electric - Power business. Jim is a member of IEEE.
Rémi Bolduc is a 1991 graduate of College of Levis Lauzon in electrodynamics. He started his working career in service and maintenance of HV apparatus for Hydro Québec. He worked for S\&C Electric Canada in assembly, services and application of MV switchgear for 6 years. For the past 10 years, he has worked for Schneider Electric and has specialized in Power Quality applications for LV and MV passive \& active PF correction systems and harmonic filters. He is presently working for Schneider Electric in France as a PFC area business development manager.

Jean-Marc Lupin is a 1984 graduate engineer in Electrical Engineering of the Grenoble Institute of Technology. His experience includes 24 years of designing power capacitors, Power Factor Correction systems and Harmonic mitigation solutions in Schneider Electric. JeanMarc is presently Innovation \& Technology Manager for PFC products in Schneider Electric - Power business

Laurent Chenevard is a graduate engineer in Electrical Engineering from Ecole Nationale Supérieure des Ingénieurs Electriciens de Grenoble. He joined Schneider Electric in 2005 in the sales department for Power Factor Correction and Harmonic Filtering activity. $\mathrm{He}$ is presently product application engineer providing technical solutions to customers regarding power quality topics. 